groups of chemicals sporadic or no positive SPTs were noted. Occupational contact urticaria (CU) caused by chemicals was diagnosed in 41 patients during the study period, 21 of them caused by acid anhydrides. More than half of the CU patients (54\%) had a concomitant allergic airway disease.

Discussion SPTs provide a fast and safe complementary tool for diagnosing immediate allergic diseases to some chemical groups, but the results should be interpreted cautiously and related to symptoms and other clinical tests. Occupational CU caused by chemicals is often accompanied by occupational airway diseases caused by the same agent.

\section{PREVALENCE OF ALLERGY RELATED SKIN AND RESPIRATORY DISEASES AMONG HEALTHCARE WORKERS IN CROATIA}

Hana Knezevic. Student, Medical school, University of Zagreb, Zagreb, Croatia

10.1136/oemed-2018-ICOHabstracts. 150

Introduction Healthcare workers are exposed to wet-work and occupational hazards such as latex, cleaning products and various medication drugs which can potentially cause allergic or irritant dermatitis and work-related rhinitis and asthma. The aim of this research was to investigate the prevalence of health issues related to the skin and respiratory tract among healthcare workers in hospital.

Methods Subjects of the research were 1021 healthcare workers employed in four clinical hospitals in Zagreb, Croatia, who filled the Work Ability Index Questionnaire. Questions about current skin diseases (allergic or other rash, eczema) and respiratory diseases (chronic or recurrent infections of the respiratory tract, bronchial asthma) diagnosed by the physician were extracted and analysed.

Result Out of 1021 healthcare workers, there were 721 nurses (47 man; 674 women) and 300 physicians (134 man; 166 women). It was found that allergic dermatitis and/or eczema was present in 15\% (109/721) nurses and in 15\% (46/300) physicians. Prevalence of respiratory diseases among nurses was 26\% (187/721), and 28\% among physicians (85/300). Coexisting skin and respiratory tract symptoms were present in $8 \%(77 / 1021)$ healthcare workers.

Discussion In this study atopic disorders and eczema were present in a significant percentage of the workers, as well as inflammation of the respiratory tract and bronchial asthma, but it couldn't be verified that symptoms are related to latex or other hazards. Individuals with a history of atopic disorders are at increased risk of latex allergy. According to ALAA, the estimated prevalence of latex allergy in healthcare workers varies between $8 \%-17 \%$. Further research in healthcare with a focus on the use of gloves, job tasks, and prevocational exposure to latex is needed.

\section{OCCUPATIONAL HAND ECZEMA AMONG CEMENT WORKERS IN NEPAL}

${ }^{1} \mathrm{SK}$ Joshi*, ${ }^{2 S}$ Bhattarai. 'Department of Community Medicine, Kathmandu Medical College, Kathmandu, Nepal; ' 2 Department of Dermatology, Kathmandu Medical College, Kathmandu, Nepal Affiliation

10.1136/oemed-2018-ICOHabstracts.151
Introduction Occupational dermatitis among cement workers is a major occupational health concern and skin contact with cement has been associated with contact dermatitis, which ranges from cement burns to cumulative irritant contact dermatitis. The objective of this study was to investigate the prevalence and severity of occupational cement contact dermatitis amongst cement workers in Nepal which is the first of its kind.

Methods This was a cross sectional descriptive study conducted amongst the workers in construction sites and hardware shops within the Kathmandu valley. A structured questionnaire was used to collect the demographic data and work-related activities of those cement workers. A complete skin examination was conducted and skin manifestations were assessed by a dermatologist. The data collected was compiled and appropriate statistical tools were used to find out the significance of variables.

Result Out of the 377 workers screened 164 (43.50\%) had hand contact dermatitis. There were males 148 (90.2\%) and females16 (9.8\%) and the age ranged from 15-51 years (mean $27.41 \pm 7.68$ years). The duration of the disease ranged from 1-360 months (median36months $(\mathrm{IQR}=60)$. The most common site of lesion was palms $(62.8 \%)$ followed by tip of the fingers in $39.0 \%$ patients and the most common morphology of the lesion was erythema seen in $59.1 \%$ followed by scaling seen in $51.8 \%$ patients.

Discussion Contact and irritant hand eczema amongst cement workers in Nepal has a considerable morbidity. Identification of these workers with adequate treatment, test of the suspected allergens and counselling could further help the workers. This study helped us to assess the magnitude of the problem and since it is a cross sectional survey, further research can be planned to see the allergens amongst the persons suspicious of contact dermatitis amongst the cement workers.

\section{MINERALOGY AND TEXTURES OF ASBESTOS: THE ROLE OF SINGLE VS AGGLOMERATED FIBRES IN TOXICOLOGICAL EXPERIMENTS}

${ }^{1} \mathrm{G}$ lezzi, ${ }^{2} \mathrm{G}$ Della Ventura, ${ }^{3}$ Manuela Nazzari, ${ }^{4} \mathrm{~F}$ Bellatreccia, ${ }^{5} \mathrm{M}$ Di Gioacchino, ${ }^{5} \mathrm{C}$ Petrarca*. ${ }^{1}$ INGEO University G. d'Annunzio of Chieti-Pescara, Chieti, Italy; ${ }^{2}$ Istituto Nazionale di Geofisica e Vulcanologia (INGV), Roma, Italy; ${ }^{3}$ INFN LNF Frascati, Roma, Italy; ${ }^{4}$ University Roma Tre, Roma, Italy; ${ }^{5}$ DMSI University G. d'Annunzio of Chieti-Pescara, Chieti, Italy

\subsection{6/oemed-2018-ICOHabstracts. 152}

Introduction Exposition to asbestos may cause adverse health effects, but a clear relationship between mineralogy and texture of fibres versus toxicity is still lacking. Toxicological studies can be properly interpreted and compared only if quantitative features of fibres are determined.

Methods Amphibole fibres were characterised by XRPD, FTIR, SEM-EDS and EMP-WDS. Fibres deposited from solutions of $0.1,1,10,25,50,75$ and $100 \mathrm{mg} / \mathrm{L}$ were counted using SEM images. The single vs agglomerated fibres was assessed. The viability of human lymphocytes exposed to the fibres was investigated by MTT test.

Results Only crystals with definite stoichiometry are present. At 0.1 and $1 \mathrm{mg} / \mathrm{L}$ the fibres are well separated, whereas between 1 and $10 \mathrm{mg} / \mathrm{L}$ they start to agglomerate. In vitro tests performed on fibres deposited at the same concentrations show that the cytotoxic effect rate decreases for asbestos concentration $>10 \mathrm{mg} / \mathrm{L}$. 
Conclusions Considering that the mineralogy is constant, the decreasing rate of toxicity suggests that the hazardous potential must be attributed mainly to the single fibres, while the agglomerated fibres, whose amount increases strongly for increasing total fibres play a minor role.

\section{$1333 \mathrm{TIO}_{2}$ AND TIO 2 -MESOPOROUS SILICA NANOPARTICLE TOXICITY EVALUATED ON PRIMARY HUMAN PERIPHERAL BLOOD MONO/LYMPHOCYTES}

${ }^{1} \mathrm{C}$ Petrarca*, ${ }^{1} \mathrm{E}$ Clemente, ${ }^{2} \mathrm{G}$ Zaccariello, ${ }^{3} \mathrm{E}$ Sabbioni, ${ }^{1} \mathrm{M}$ Di Gioacchino. ${ }^{1}$ University ' $\mathrm{G}$. d'Annunzio' of Chieti-Pescara, Chieti, Italy; '2University Ca' Foscari of Venezia, VeneziaMestre, Italy; Italian Society of Nanotoxicology, Rome, Italy

\subsection{6/oemed-2018-ICOHabstracts.153}

Introduction $\mathrm{TiO}_{2}-\mathrm{NPs}$ are the most produced nanomaterial as UV filters. They are considered as nontoxic at the exposure levels of the occupational environments; nevertheless, potentially dangerous organic molecules can be formed due to photocatalysis. Mesoprous silica $\left(\mathrm{SiO}_{2}\right)$ nanoparticles (MSN) incorporating Ti-nano were produced to improve their properties. We studied whether human lymphocytes/monocytes can be the target of a toxic action of all these NPs.

Methods Activated/quiescent huPBMCs were exposed ex-vivo to: $\mathrm{TiO}_{2}$-NPs $(21 \mathrm{~nm}) ; \mathrm{MSN}(100 \mathrm{~nm}) ; \mathrm{TiO}_{2}-\mathrm{MSN}$ (4.4 nm $\mathrm{TiO}_{2}$ into MSN pores). They were characterised for: cell viability/apoptosis by MTT and Annexin-V; ROS by DCFH oxidation; nuclear morphology by fluorescence microscopy; cytokines by ELISA.

Results The viability of activated lymphocytes exposed to the highest doses all NPs was significantly reduced. All NPs induced apoptosis, but only $\mathrm{TiO}_{2}$-NPs induced ROS. IL-2, IL17, IFN-g were downmodulated by all; MSNs were associated with increased IL- $1 \beta$ and IL-4 secretion; $\mathrm{TiO}_{2}-\mathrm{NPs}$ induced IL10 , TNF- $\alpha$ and IL-23.

Conclusion Different patterns of cytokine in response to the three different NPs tested: they are all immunosuppressive, but only $\mathrm{TiO}_{2}$-MSN seem to act as pro-inflammatory and proallergic agents. The presence of $\mathrm{TiO}_{2}$ in MSN appear to influence the effects of these larger NPs, possibly related to its pro-oxidative and pro-apoptotic effect.

\section{OCCUPATIONAL EXPOSURE TO IMMUNOTOXICANTS AND SOLAR RADIATION IN THE FRAMEWORK OF THE ONGOING CLIMATE CHANGE: ANOTHER STEP IN EXPOSOME PROFILING}

C Grandi*, MC D'Ovidio. INAIL - Dept. of Occupational and Environmental Medicine, Epidemiology and Hygiene, Monte Porzio Catone (RM), Italy

\subsection{6/oemed-2018-ICOHabstracts. 154}

Introduction Immunotoxicants may interfere with one or more mechanisms involved in the elicitation of the immune response. Occupational exposure to solar radiation may exert an immunosuppressive effect, both locally and systemically, while the ongoing climate change may alter the occupational exposure to both solar radiation and number of immunotoxicants.

Methods Literature review on occupational exposure to immunotoxicants as well as to solar radiation and climate change.

Results Metals, solvents, some pesticides and other categories of chemicals currently used in or released by working processes are immunotoxic. Outdoor workers may be simultaneously exposed to both immunotoxicants and solar radiation. Moreover, a changing climate may increase or, depending on some factors involved, decrease the occupational exposure to both immunotoxicants and solar radiation. The net effect on the overall immune response is difficult to predict, depending on the combination and levels of the exposures involved and the outcome considered (for instance immune response to pathogens vs allergic/sensitisation reactions).

Discussion The protection of outdoor workers from the effects due to combined exposure to immunotoxicants, solar radiation and variables connected to climate change needs a careful assessment of all the factors involved, having care to acquire the immune profile of the worker during the health surveillance, through both conventional and innovative approaches. In addition, co-exposure to chemical or physical agents (e.g. irritants, sensitizers, high temperatures and humidity) modulating the effect/s of a given level of exposure to a single immunotoxicant or to a combination of immunotoxicants has to be taken into account. As a perspective, the implementation of this topic may contribute to define the 'exposome' of important categories of outdoor workers.

\section{HANDLING AND DISPOSAL OF AGRICULTURAL CHEMICALS ON A2 FARMS IN CHIRUMHANZU DISTRICT}

Matunhu Viola. Midlands State University

\subsection{6/oemed-2018-ICOHabstracts. 155}

In 2000 the Government of Zimbabwe undertook a massive land redistribution programme under its black economic empowerment policy where white-owned farms were seized and sub-dividing into smaller A1 and A2 models and redistributed to landless black majority. However, most of the land beneficiaries were ill-resourced and ill-trained to use the land in an ecologically friendly manner. This paper investigated how newly resettled farmers handled and disposed agricultural chemicals on the acquired A2 farms. In-depth interviews and observation where the main data collection instruments. The study involved farm employees on A2 farms that use agrochemicals to enhance farm productivity. A total of 150 respondents participated in the study. The findings of this study indicated that despite the availability of statutory provisions on handling and disposal of agricultural chemicals, there is rampant mismanagement of environmentally unfriendly chemicals on the farms. Although most of the employees on the farms are literate, they find it difficult to understand the technical jargon used on these chemical labels. The study also established that agricultural chemicals are vital in sustaining Zimbabwe's agricultural sector in terms of food security, foreign exchange generation, employment and provision of raw material for the manufacturing sector. On the other hand mismanagement of these chemicals can have adverse effects on human beings and the environment. It is therefore, important for farmers and their employees to be trained on personal, public health and environmental implications of poor management of agricultural chemicals. The paper recommends that the Zimbabwean Government should adopt a multi-sectoral campaigns strategy against mismanagement of agricultural chemicals. Use of electronic and print media of communication through the local languages is also recommended. 